\title{
Age-related Worm Load and Worm Fecundity Patterns in Human Populations, as Indicated by Schistosome Circulating Antigens
}

\author{
Katja Polman+, L Van Lieshout, B Gryseels, AM Deelder
}

Department of Parasitology, University of Leiden, P.O. Box 9605, 2300 RC Leiden, The Netherlands

Recently, our group determined the relationship between serum CAA levels and fecal egg counts in two foci with very intense Schistosoma mansoni transmission: Maniema (Zaire), an area endemic for $\mathrm{S}$. mansoni since several decades, and Ndombo (Senegal), where transmission has only been established since a few years. The objective was to study and compare age-related worm load and worm fecundity patterns in these two different endemic settings. Here, we will summarize the most important findings and conclusions of this study.

Key words: Schistosoma mansoni - circulating anodic antigen (CAA) - worm load - worm fecundity

To study the dynamics of schistosome infections, an accurate measure of worm burden is of major importance. However, due to their intra-vascular localization, Schistosoma mansoni worm numbers cannot be directly quantified in infected humans, and one has to rely on indirect methods, like the counting of eggs in feces (Katz et al. 1972, De Vlas \& Gryseels 1992).

An alternative measure of schistosome infections is the detection of circulating anodic antigen (CAA) in serum (Deelder et al. 1989, 1994), which may provide a more direct assessment of worm loads than fecal egg counts. CAA is a glycoconjugate associated with the gut of the adult worm and released by the parasite in large amounts into the circulation of the infected host. CAA detection in serum appears to give a quantitatively stable diagnosis of $S$. mansoni infection (Polman et al. 1998). Several animal studies have shown a good correlation between worm loads and CAA levels (Deelder et al. 1994, Agnew et al. 1995).

By interpreting antigen levels as a direct reflection of worm load, it would be possible to describe the distributions and dynamics of $S$. mansoni infection in more depth than with egg counts only. Especially mechanisms like density-dependent fecundity and anti-fecundity immunity, could be very well studied by comparing antigen levels (representing worm load) and fecal egg counts in different endemic settings (Polman et al. 1995, Van Lieshout et al. 1995, Agnew et al. 1996).

\footnotetext{
${ }^{+}$Corresponding author. Fax: +31-71-527.6850. E-mail: polman@rullf2.medfac.leidenuniv.nl Received 4 May 1998 Accepted 31 August 1998
}

Recently, by our group, the relationship between serum CAA levels and fecal egg counts was determined in two endemic settings with very intense S. mansoni transmission: Maniema (Zaire), an area endemic for $S$. mansoni since several decades, and Ndombo (Senegal), where transmission has only been established since a few years (Van Lieshout et al. 1997).

In both foci, it was examined whether CAA levels, as a direct measure of worm burden, confirmed the age-related pattern suggested by egg counts, and whether in the respective age groups the relation between CAA levels and egg counts suggested density-dependent fecundity.

Also, the relationship between CAA levels and egg output was compared between the two areas, to see whether this was influenced by the history of exposure on a population level. Due to the epidemic increase of schistosomiasis in Ndombo, most individuals had probably become infected within a relatively short time frame. In this situation history of infection should thus not be related to age, in contrast to the situation in Maniema (Gryseels et al. 1995). Also, according to the current hypothesis in which resistance develops only slowly after several years of infection, acquired immunity should still be absent in Ndombo, while present in Maniema (Butterworth et al. 1992, Gryseels 1994).

In the next paragraphs, we will give a summary of the most important findings and conclusions of this study, as described in detail by Van Lieshout et al. (1997).

Both datasets, Maniema $(\mathrm{n}=508)$ and Ndombo $(n=246)$, were collected according to the same standardized methods with similar protocols of parasitological examination (i.e. two duplicate $25 \mathrm{mg}$ Kato-slides) and circulating antigen determination 
(Polderman et al. 1985a, b, Stelma et al. 1993, Polman et al. 1995, Van Lieshout et al. 1995, 1997).

Based on fecal egg counts, S. mansoni infection levels were found to be extremely high and remarkably similar in both communities. In contrast to egg counts, CAA levels differed significantly between the two groups. Mean CAA levels were higher in Maniema than in Ndombo, also after stratification into separate egg count classes.

Both communities showed the characteristic age-related pattern of egg counts, except for a more pronounced peak in Ndombo in the age group of 10-14 years. Likewise, CAA levels showed a rapid increase in young children and a peak level around 5-15 years in both populations, but thereafter antigen levels decreased in the Ndombo population to a much lower plateau. This sharp drop of CAA levels in adolescents from Ndombo, suggests comparatively higher worm fecundity in adult hosts in this recent focus.

For more detailed comparison, both communities were divided into four age groups and regression analysis was performed. In both populations, the relationship between CAA levels and egg counts was found to be nonlinear, i.e. at high antigen levels, egg counts were not as high as expected in case of a linear relationship. This agrees with the theory of density-dependent fecundity, i.e. a decreased egg production by female worms in the case of high worm loads (Medley \& Anderson 1995). However, the phenomenon of density-dependent fecundity is still a point of debate (Wertheimer et al. 1987, Gryseels \& De Vlas 1996).

In Maniema, the relationship between CAA levels and egg counts was found to be constant at different age groups, indicating that the reduction in egg counts seen in adults after a peak during adolescence is caused by a genuine reduction in worm burden rather than reduced worm fecundity with age of the host. However, in Ndombo, significant differences were found between age groups. This effect of age seemed to be a combination of several factors, not clearly attributable to one parameter.

The differences that were found in the relation between CAA levels and egg counts after comparison of the two groups, suggest that in case antifecundity immunity would be of any importance in S. mansoni infections, it seems to be more related to the history of transmission for the total population, than to exposure experience on an individual level. We have no explanation for the fact that worm fecundity in young children from Ndombo seems to be relatively low compared to adults in this area and is more similar to the Maniema population.
All these findings are based on the assumption that serum CAA levels do reflect actual worm loads, irrespective of the intensity of infection or the immune status of the host (Agnew et al. 1995). Still, it can not be ruled out that the production and/or clearance of CAA is affected by several, in part host-related, mechanisms (Van Lieshout et al. 1995). For example, the efficiency of the immune system to clear CAA may be influenced by age or health status of the host, as well as by previous experience of infection. Alternatively, the production of CAA may depend on geographical strain differences of the parasite, or the age of the worms. To gain a better understanding on the mechanisms of production and/or clearance of antigens, more research on these issues is definitely needed.

In conclusion, estimation of worm burdens in humans by serum CAA determination appears to be a valuable approach, which can provide important complementary information on the dynamics of $S$. mansoni infections in humans.

At this moment, we are also collecting CAA detection results from other $S$. mansoni endemic areas, in order to study the relation between worm burdens and egg production in each specific endemic situation, as well as on a comprehensive level.

We are also trying to include circulating antigens in a mathematical model based on egg counts, as developed by De Vlas et al. (1992). In this way, we intend to study the relation between worm burdens, antigen levels and egg counts in a more refined way, than has so far been possible through regression analysis.

\section{REFERENCES}

Agnew AM, Fulford, AJC, De Jonge N, Krijger FW, Rodriguez-Chacon M, Gutsmann V, Deelder AM 1995. The relationship between worm burden and levels of a circulating antigen (CAA) of five species of Schistosoma in mice. Parasitology 111: 67-76.

Agnew AM, Fulford AJC, Mwanje MT, Kimani G, Gutsmann V, Krijger FW, Sturrock, RF, Vennervald BJ, Ouma JH, Butterworth AE, Deelder AM 1996. Age-dependent reduction of schistosome fecundity in Schistosoma haematobium but not Schistosoma mansoni infections in humans. Am J Trop Med Hyg 53: 338-343.

Butterworth AE, Dunne DW, Fulford AJC, Thorne KJI, Gachuhi K, Ouma JH, Sturrock RF 1992. Human immunity to Schistosoma mansoni: observations on mechanisms, and implications for control. Immunol Invest $21: 391-407$.

Deelder AM, De Jonge N, Boerman OC, Fillié YE, Hilberath GW, Rotmans JP, Gerritse MJ, Schut DWOA 1989. Sensitive determination of circulating anodic antigen in Schistosoma mansoni infected individuals by an enzyme-linked immunosorbent 
assay using monoclonal antibodies. Am J Trop Med Hyg 40: 268-272.

Deelder AM, Qian ZL, Kremsner PG, Acosta L, Rabello ALT, Enyong P, Simarro PP, Van Etten ECM, Krijger FW, Rotmans JP, Fillié YE, De Jonge N, Agnew AM, Van Lieshout L 1994. Quantitative diagnosis of Schistosoma infections by measurement of circulating antigens in serum and urine. Trop Geogr Med 46: 233-238.

De Vlas SJ, Gryseels B 1992. Underestimation of Schistosoma mansoni prevalences. Parasitol Today 8: 274-277.

De Vlas SJ, Gryseels B, Van Oortmarssen GJ, Polderman AM, Habbema JDF 1992. A model for variations in single and repeated egg counts in Schistosoma mansoni infections. Parasitology 104: 451-460.

Gryseels B 1994. Human resistance to Schistosoma infections: Age or experience? Parasitol Today 10: 380-384.

Gryseels B, De Vlas SJ 1996. Worm burdens in schistosome infections. Parasitol Today 12: 115-119.

Gryseels B, Stelma FF, Talla I, Polman K, Van Dam GJ, Sow S, Diaw M, Sturrock RF, Decam C, Niang M, Deelder AM 1995. Immuno-epidemiology of Schistosoma mansoni infections in a recently exposed community in Senegal. Mem Inst Oswaldo Cruz 90: 271-276.

Katz N, Chaves A, Pellegrino J 1972. A simple device for quantitative stool thick-smear technique in schistosomiasis mansoni. Rev Inst Med Trop São Paulo 14: 397-400.

Medley G, Anderson RM 1985. Density-dependent fecundity in Schistosoma mansoni infections in man. Trans $R$ Soc Trop Med Hyg 79: 532-534.

Polderman AM, Mpamila K, Manshande JP, Bouwhuis-Hoogerwerf ML 1985a. Methodology and interpretation of parasitological surveillance of intestinal schistosomiasis in Maniema, Kivu Province, Zaire. Ann Soc belge Méd Trop 65: 243-249.

Polderman AM, Mpamila K, Manshande JP, Gryseels
B, Van Schayk O 1985b. Historical, geological and ecological aspects of transmission of intestinal schistosomiasis in Maniema, Kivu Province, Zaire. Ann Soc belge Méd Trop 65: 251-261.

Polman K, Engels D, Fathers L, Deelder AM, Gryseels B 1998. Day-to-day fluctuation of schistosome circulating antigen levels in serum and urine of humans infected with Schistosoma mansoni in Burundi. Am J Trop Med Hyg 59: 150-154.

Polman K, Stelma FF, Gryseels B, Van Dam GJ, Talla I, Niang M, Van Lieshout L, Deelder AM 1995. Epidemiological application of circulating antigen detection in a recent Schistosoma mansoni focus in Northern Senegal. Am J Trop Med Hyg 53: 152-157.

Stelma FF, Talla I, Polman K, Niang M, Sturrock RF, Deelder AM, Gryseels B 1993. Epidemiology of Schistosoma mansoni infection in a recently exposed community in Northern Senegal. Am J Trop Med Hyg 49: 701-706.

Van Dam GJ, Bogitsh BJ, Van Zeyl RJM, Rotmans JP, Deelder AM 1996 Schistosoma mansoni: in vitro and in vivo excretion of CAA and CCA by developing schistosomula and adult worms. J Parasitol 82 : 557-564.

Van Lieshout L, Polderman AM, De Vlas SJ, De Caluwé P, Krijger FW, Gryseels B, Deelder AM 1995. Analysis of worm burden variation in human Schistosoma mansoni infections by determination of serum levels of circulating anodic antigen and circulating cathodic antigen. J Infec Diseases 172: 1336-1342.

Van Lieshout L, Polman K, Gryseels B, Deelder AM 1997. Comparison of circulating antigen levels in two areas endemic for schistosomiasis mansoni indicates differences in worm fecundity. Transactions (in press).

Wertheimer SP, Vermund SH, Lumey LH, Singer B 1987. Lack of demonstrable density-dependent fecundity of schistosomiasis mansoni: analyses of Egyptian quantitative human autopsies. Am J Trop Med Hyg 37: 79-84. 
